\title{
Biometric differences between several populations of Cordulegaster boltonii (Odonata: Cordulegastridae) in Ibero-Maghrebian area
}

\author{
Patricia CasanueVA ${ }^{1}$, Tomás SANTAMaría ${ }^{2}$, María Á. HeRnÁNDEZ ${ }^{3}$, Luis F. SÁNCheZ-SASTRE ${ }^{4}$, Amilcar \\ TEIXEIRA ${ }^{5}$, NARd BENNAS ${ }^{6}$, MoHamed EL HAISSOUFI ${ }^{7}$, MANUEL FERRERAS-ROMERO ${ }^{8}$ and FRANCISCO CAMPOS ${ }^{1}$ \\ ${ }^{1}$ Departamento de Ciencias Experimentales, Universidad Europea Miguel de Cervantes, Calle Padre Julio Chevalier 2, \\ E-47012 Valladolid, Spain; e-mails: pcasanueva@uemc.es, fcampossb@gmail.com \\ 2 Universidad Católica de Ávila, Calle Canteros s/n, E-05005 Ávila, Spain; e-mail: tomas.santamaria@ucavila.es \\ ${ }^{3}$ Departamento de Biología Ambiental, Facultad de Ciencias, Universidad de Navarra, E-31080 Pamplona, Spain; \\ e-mail: mahermin@unav.es \\ ${ }^{4}$ Universidad de Valladolid, ETSIIAA, Campus La Yutera, Av. Madrid 44, 34004 Palencia, Spain; e-mail: luxpher@gmail.com \\ ${ }^{5}$ Escola Superior Agraria, Instituto Politécnico de Bragança, 5300-253 Bragança, Portugal; e-mail: amilt@ipb.pt \\ ${ }^{6}$ Département de Biologie, Université Abdelmalek Essaâdi, Faculté des Sciences, Tétouan, Morocco; \\ e-mail: nbennas@hotmail.com \\ ${ }^{7}$ Department of Biology, Chemistry and Geology, Polydisciplinary Faculty of Taza, Sidi Mohamed Ben Abdellah University, Fes, \\ Morocco; e-mail: med.elhaissoufi@gmail.com \\ ${ }^{8}$ Departamento de Sistemas Físicos, Químicos y Naturales, Universidad Pablo de Olavide, A-376 km 1, 41013 Sevilla, Spain; \\ e-mail: mferrom@upo.es
}

Key words. Odonata, Cordulegastridae, Cordulegaster boltonii, biometrics, dragonflies, mountain streams, Iberian Peninsula, Morocco

\begin{abstract}
Biometric data of the exuviae of female larvae of the dragonfly Cordulegaster boltonii collected in Portugal, Spain and Morocco were analysed to determine whether the size of three exuvial structures measured differed depending on the geographic localities of the populations. Based on the results recorded for the 16 populations studied, head width was negatively correlated with latitude and the greatest length of the gonapophysis was recorded for the Iberian populations at the centre of this peninsula. Multivariate cluster analysis revealed a clear separation of the Moroccan population. A second cluster separated the southernmost population (Sierra Nevada) from the remaining Iberian populations. Four population groups were distinguished: those located in watercourses in the north and central area of the Iberian Peninsula, those in Iberian watercourses in the East and Middle South, the Sierra Nevada and North Morocco. Some of these results coincide with the results of genetic studies of other authors.
\end{abstract}

\section{INTRODUCTION}

Morpho-biometric characters of Odonata have been used to confirm interspecific differences recorded by genetic analysis (Lee \& Lin, 2012; Kohli et al., 2013). These characters enable species to be differentiated during the larval phase when other characters are not consistent or difficult to observe (Landwer \& Sites, 2006), can be used to analyse the parallel evolution of species in the same genus (Stoks et al., 2005) and to relate genome size with body size (Ardila-García \& Gregory, 2009). Similarly, they have been utilized to separate specimens or populations of the same species, either by analysing adults (e.g., Cabuga et al., 2017; Corso, 2019) or exuviae (Casanueva et al., 2017a).

During the larval stages odonates are preyed upon by other species, mainly fish (Morin, 1984; McPeek, 1990). Many species defend themselves by means of abdominal spines against predators (Arnqvist \& Johansson, 1998; Johansson, 2002; Johansson
\& Wahlström, 2002; McCauley et al., 2008). This feature is phenotypically plastic and larger where there are predators, which does not incur costs such as a longer larval development time or increase in the body size of F-0 larvae (Johansson, 2002).

The larvae of Cordulegaster boltonii (Donovan, 1807) behave like burrowers (Corbet, 2004) and their physiognomy has been analysed by Verschuren (1989) and Boudot \& Jacquemin (1995). Along with other anatomical structures, these authors measured the size of the lateral spines on abdominal segments 8 and 9 , setae of these segments and the gonapophysis.

The aim of this work was to determine whether certain morpho-biometric characters of the exuviae (head width, gonapophysis length and relative size of the lateral spines) are useful for grouping C. boltonii populations over a wide geographical area. If so, do they support the results for the same area of a genetic analysis and/or morphometric analysis of other body structures. 


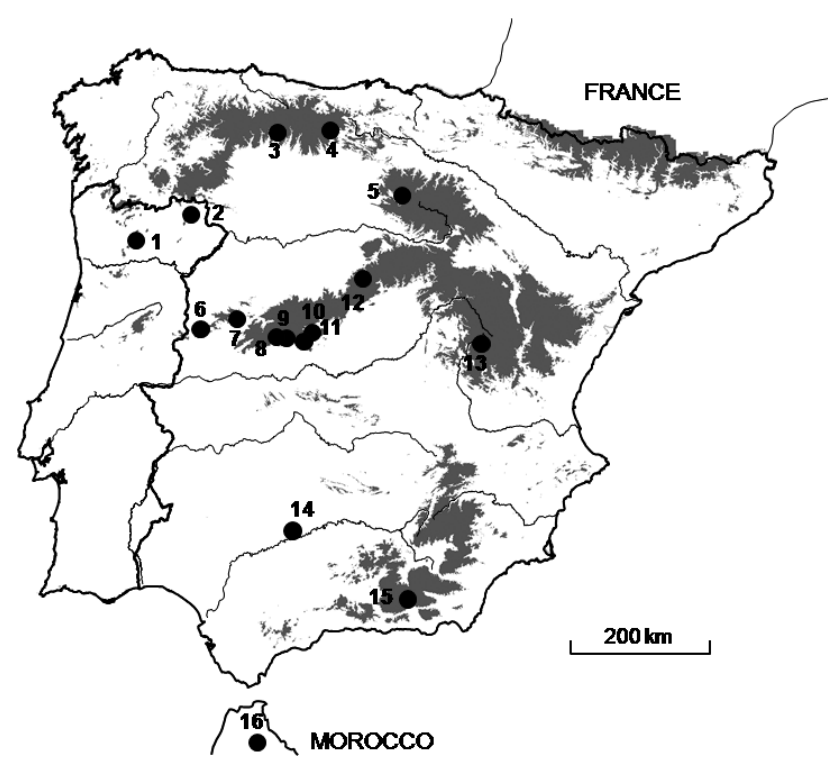

Fig. 1. Map showing the distribution of the 16 rivers sampled (black dots) on the Iberian Peninsula and in Morocco. 1 - Cova, 2 - Sabor 3 - Curueño, 4 - Lazán, 5 - Arlanzón, 6 - Frío, 7 - Francia, 8 Tormes, 9 - Barbellido, 10 - Gama, 11 - Alberche, 12 - Cega, 13 - Júcar, 14 - Bejarano, 15 - Monachil, 16 - Amsemlil (Morocco). Grey areas are mountain ranges: altitude $>1000 \mathrm{~m}$ a.s.l.

\section{MATERIAL AND METHODS}

During 2016 and 2017 exuviae of final instar larvae of C. boltonii were collected from fourteen mountain rivers on the Iberian Peninsula and one in Morocco (Fig. 1, Table 1). In addition, exuviae that were collected from 1989-1992 from the population in the Bejarano River were also used. All samples were collected in May, June and July, which for this species is the period when most adults emerge (Ferreras-Romero \& Corbet, 1999; Casanueva et al., 2017b). In the laboratory, the exuviae were measured, always by the same person (FC), using a Nikon SMZ800 binocular microscope with an eyepiece micrometre. Since males do not have a gonapophysis, only female exuviae were used.

Based on the work of Verschuren (1989), Boudot \& Jacquemin (1995) proposes three criteria of exuviae for differentiating populations of C. boltonii: (a) form of the setae on the posterior edge of the 9th sternite, (b) ratio of the length of the lateral spine on

Table 1. Geographic coordinates and sample sizes $(\mathrm{N})$ of exuviae of female Cordulegaster boltonii from 16 populations. Altitude: $\mathrm{m}$ a.s.l.

\begin{tabular}{lcccrr}
\hline River & Country & North & West & Altitude & N \\
\hline 1. Cova & Portugal & $41^{\circ} 35^{\prime}$ & $7^{\circ} 47^{\prime}$ & 329 & 11 \\
2. Sabor & Portugal & $41^{\circ} 54^{\prime}$ & $6^{\circ} 44^{\prime}$ & 665 & 36 \\
3. Curueño & Spain & $42^{\circ} 50^{\prime}$ & $5^{\circ} 24^{\prime}$ & 1001 & 33 \\
4. Lazán & Spain & $43^{\circ} 01^{\prime}$ & $4^{\circ} 28^{\prime}$ & 1210 & 38 \\
5. Arlanzón & Spain & $42^{\circ} 13^{\prime}$ & $3^{\circ} 18^{\prime}$ & 1170 & 25 \\
6. Frío & Spain & $40^{\circ} 19^{\prime}$ & $6^{\circ} 38^{\prime}$ & 830 & 50 \\
7. Francia & Spain & $40^{\circ} 30^{\prime}$ & $6^{\circ} 02^{\prime}$ & 595 & 28 \\
8. Tormes & Spain & $40^{\circ} 20^{\prime}$ & $5^{\circ} 10^{\prime}$ & 1380 & 59 \\
9. Barbellido & Spain & $40^{\circ} 19^{\prime}$ & $5^{\circ} 12^{\prime}$ & 1450 & 49 \\
10. Gama & Spain & $40^{\circ} 25^{\prime}$ & $5^{\circ} 12^{\prime}$ & 1642 & 26 \\
11. Alberche & Spain & $40^{\circ} 26^{\prime}$ & $5^{\circ} 03^{\prime}$ & 1425 & 33 \\
12. Cega & Spain & $41^{\circ} 02^{\prime}$ & $3^{\circ} 49^{\prime}$ & 1255 & 43 \\
13. Júcar & Spain & $40^{\circ} 19^{\prime}$ & $1^{\circ} 48^{\prime}$ & 1245 & 22 \\
14. Bejarano & Spain & $37^{\circ} 56^{\prime}$ & $4^{\circ} 52^{\prime}$ & 400 & 42 \\
15. Monachil & Spain & $37^{\circ} 07^{\prime}$ & $3^{\circ} 30^{\prime}$ & 1016 & 49 \\
16. Amsemlil & Morocco & $35^{\circ} 15^{\prime}$ & $5^{\circ} 25^{\prime}$ & 1053 & 46 \\
\hline
\end{tabular}

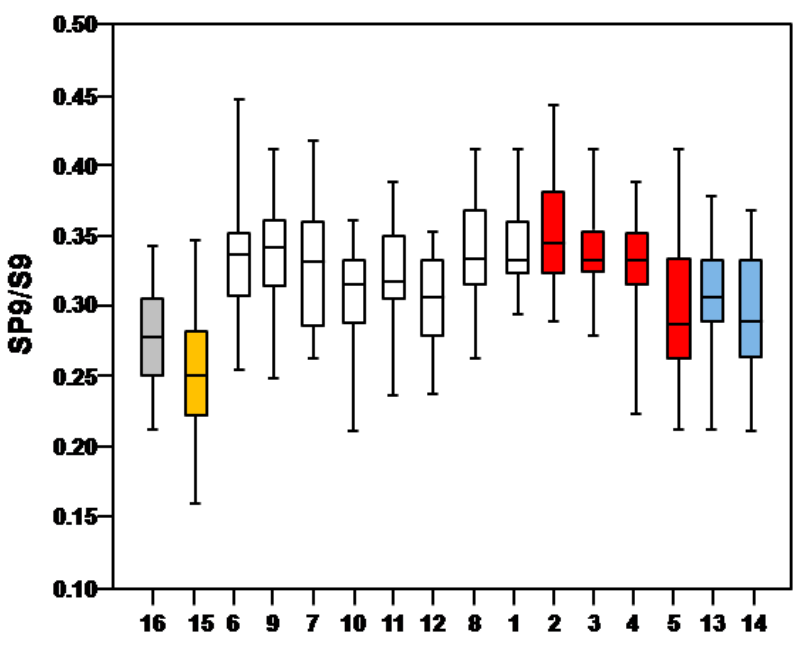

Fig. 2. Boxplot of the SP9/S9 values for the 16 Cordulegaster boltonii populations analysed. The numbers correspond to those in Fig. 1 and are arranged according to the dendrogram in Fig. 5. Grey - cluster A, orange - cluster B, white - cluster D1, red cluster D2, blue - cluster C. Bars: upper and lower values. Boxes: upper $(75 \%)$ and lower (25\%) percentiles. Line in box - median.

the 9th sternite (SP9) and length of the 9th sternite (S9), which is SP9/S9, and (c) length of gonapophysis (LG). The first is a morphological character and therefore not quantifiable, while the other two are easily quantifiable. The last two were used in this study. An additional quantifiable character was also utilized; head width (He; i.e. the maximum distance between the lateral margins of the compound eyes), which does not vary during the emergence period (Casanueva et al., 2017c). These three variables are very poorly correlated, so collinearity is avoided (LG-SP9/S9: $r=$ 0.30; LG-He: $r=-0.03$; He-SP9/S9: $r=-0.12$ ). The $\mathrm{LG}$ and He variables were adjusted to normality using the Shapiro-Wilk test, which then met the homogeneity of variance based on the Bartlett's test. Therefore, their average values were compared using an analysis of variance ANOVA. The SP9/S9 ratio values do not adjust to normality, so it was necessary to use the Kruskal-Wallis non-parametric analysis. In all cases the minimum significance value was $\mathrm{P}<0.05$.

A multivariate cluster analysis was used to group the variables by achieving the maximum homogeneity in each group and greatest difference between groups. For this, the nearest neighbour, similarity index or Euclidean distance was used as an algorithm. Clusters were joined based on the smallest distance between two groups. With a bootstrapping of $\mathrm{N}=10000$, the percentage support was calculated for each of the nodes.

\section{RESULTS}

Measurements of 590 exuviae collected from sixteen Iberian and Maghrebi populations were analysed (Table 1). There were significant differences between populations for the SP9/S9 ratio (Kruskal-Wallis test, $\mathrm{H}=212.18, \mathrm{P}=0.000), \mathrm{LG}\left(\mathrm{F}_{15,571}=65.66\right.$, $\mathrm{P}=0.000)$ and $\mathrm{He}\left(\mathrm{F}_{15,571}=54.06, \mathrm{P}=0.000\right)$. The SP9/S9 ratio did not clearly separate between the populations sampled, but the highest values were recorded for the northern and central populations and the lowest for the southernmost Iberian Peninsula (Monachil, located at Sierra Nevada) and Moroccan populations (Fig. 2). The populations at the centre of the Iberian Peninsula (Tormes and Alberche) had a longer gonapophysis than the other populations and the shortest was recorded for the Monachil population (Fig. 3). The head of the exuviae from Morocco was the widest (Fig. 4) followed by those from the Middle South and East 


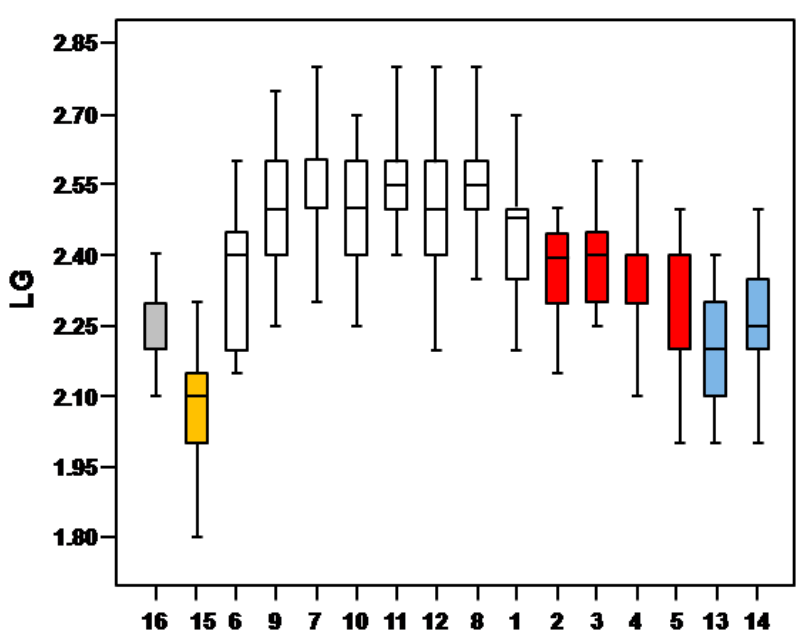

Fig. 3. Boxplot of the gonapophysis lengths (LG, in $\mathrm{mm}$ ) for the 16 Cordulegaster boltonii populations analysed. The numbers correspond to those in Fig. 1 and are arranged according to the dendrogram in Fig. 5. Grey - cluster A, orange - cluster B, white - cluster D1, red - cluster D2, blue - cluster C. Bars: upper and lower values. Boxes: upper $(75 \%)$ and lower $(25 \%)$ percentiles. Line in box - median.

Iberian Peninsula populations (Bejarano and Júcar). The head width was negatively correlated with latitude.

Multivariate cluster analysis (Fig. 5) clearly separates the Moroccan population (Amsemlil) from the others. A second cluster separates, with a difference of $70 \%$, the southernmost population (Monachil), which hereafter is called cluster B, from the other clusters, which are referred to hereinafter as clusters $\mathrm{C}$ and $\mathrm{D}$. Clusters C and D differ by $33 \%$. Cluster D includes the central and northern Iberian populations within which there are two groups that differ by $70 \%$ : cluster D1 including the seven populations in the centre and one from the north of Portugal, and cluster D2 including the four northernmost populations studied.

Since this analysis indicates that the Moroccan and Monachil populations differ from all others, they were not included in the non-parametric ANOVA used to determine whether clusters C, D1 and D2 differ from each other (Table 2). These analyses indicate that the variables He, GL and SP9/S9 differ significantly

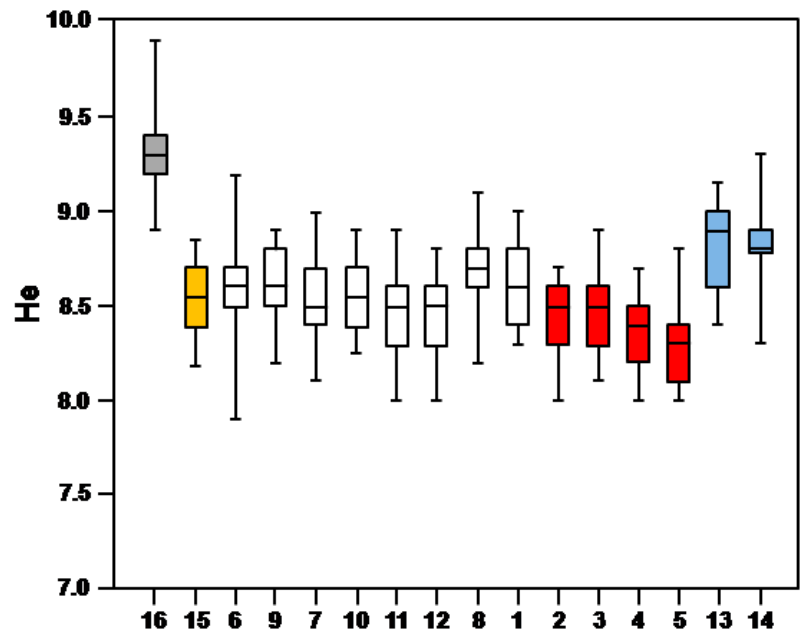

Fig. 4. Boxplot of the head widths ( $\mathrm{He}$, in $\mathrm{mm}$ ) for the 16 Cordulegaster boltonii populations analysed. The numbers correspond to those in Fig. 1 and are arranged according to the dendrogram in Fig.5. Grey - cluster A, orange - cluster B, white - cluster D1, red cluster D2, blue - cluster C. Bars: upper and lower values. Boxes: upper $(75 \%)$ and lower $(25 \%)$ percentiles. Line in box - median.

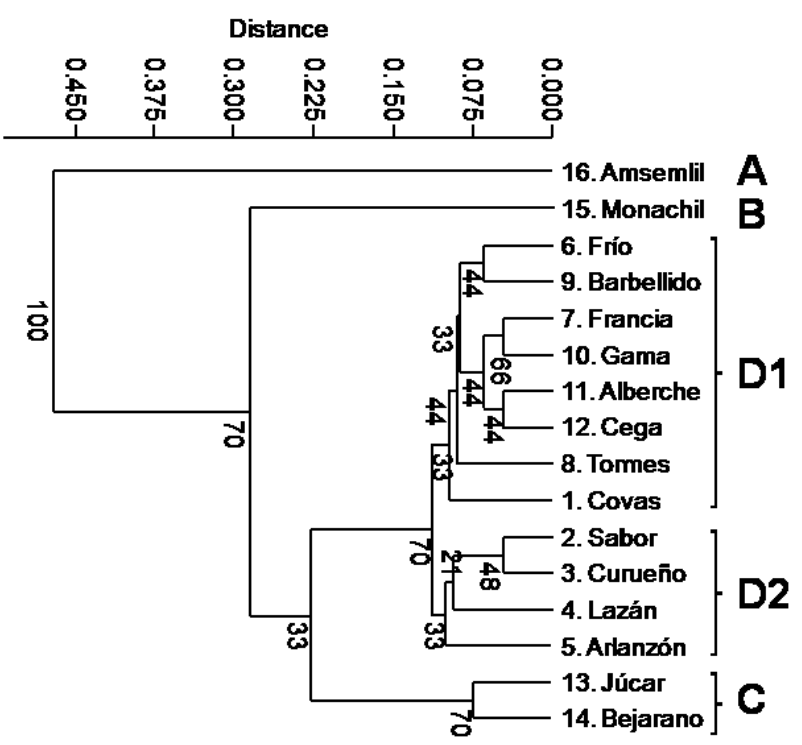

Fig. 5. Dendrogram of the 16 populations analysed based on the head widths, gonapophysis lengths and SP9/S9 ratios. The population numbers are the same as those in Fig. 1. Numbers at nodes refer to bootstrap support for that particular branch.

$(\mathrm{P}=0.000)$, both when the three clusters are compared separately and when $\mathrm{C}$ is compared with D1 and D2 combined (Table 2). However, when clusters D1 and D2 were compared with each other, the SP9/S9 ratio did not differ significantly $(\mathrm{P}=0.249)$.

\section{DISCUSSION}

Based on the results the sixteen populations analysed form four groups: (A) North Africa, the population located in the Rif Mountains in northern Morocco, (B) southernmost Iberian Peninsula, Sierra Nevada population, (C) East and Middle South of the Iberian Peninsula, with two populations, and (D) Centre and North of the Iberian Peninsula, with twelve populations. In the D group there are two subgroups, one consisting of the four northernmost populations on the Iberian Peninsula and another consisting of seven populations in central Spain plus one in northern Portugal.

This grouping coincides only partially with the one proposed by Boudot \& Jacquemin (1995) who analysed exuviae of C. boltonii from the Iberian Peninsula and Morocco. These authors suggest that the South Iberian populations have a mixture of the characteristics of the populations in North Africa and those at the centre of the Iberian Peninsula and those of the northern Iberian populations differ from those at the centre of the peninsular. On the other hand, Froufe et al. (2013) conclude that, of the populations they studied, only that in North Africa ( C. boltonii algirica) is genetically different from the populations in Europe. This same difference also appears when the biometric characteristics of the exuviae were studied.

Table 2. Values of the ANOVA between clusters D1, D2 and C for head width $(\mathrm{He})$, gonapophysis length (LG) and ratio of the lateral spine length (SP9) and length (S9) of the ninth abdominal segment of exuviae of female Cordulegaster boltonii from 16 populations. $\mathrm{P}$ - probability.

\begin{tabular}{ccccccc}
\hline \multicolumn{2}{c}{ D1-D2 } & \multicolumn{2}{c}{ D1-D2-C } & \multicolumn{2}{c}{$(\mathrm{D} 1-\mathrm{D} 2)-\mathrm{C}$} \\
\hline $\mathrm{He}$ & $\mathrm{F}_{(1,428)}$ & 66.84 & $\mathrm{~F}_{(2,492)}$ & 88.84 & $\mathrm{~F}_{(1,493)}$ & 96.11 \\
& $\mathrm{P}$ & 0.000 & $\mathrm{P}$ & 0.000 & $\mathrm{P}$ & 0.000 \\
LG & $\mathrm{F}_{(1,428)}$ & 131.20 & $\mathrm{~F}_{(2,492)}$ & 166.38 & $\mathrm{~F}_{(1,493)}$ & 157.92 \\
& $\mathrm{P}$ & 0.000 & $\mathrm{P}$ & 0.000 & $\mathrm{P}$ & 0.000 \\
SP9/S9 & $\mathrm{F}_{(1,428)}$ & 1.330 & $\mathrm{~F}_{(2,492)}$ & 20.50 & $\mathrm{~F}_{(1,493)}$ & 39.61 \\
& $\mathrm{P}$ & 0.249 & $\mathrm{P}$ & 0.000 & $\mathrm{P}$ & 0.000 \\
\hline
\end{tabular}


According to Froufe et al. (2013), it seems likely that North Africa was colonized twice, once by a common ancestor of Cordulegaster princeps (Jacquemin \& Boudot, 1999) and C. boltonii, and more recently by $C$. boltonii. However, adults in Czech populations of $C$. boltonii only make short trips $(<10 \mathrm{~km})$ (Hančíková, 2014). If the same occurs on the Iberian Peninsula and in Morocco, it is possible that the populations of $C$. boltonii on both sides of the Mediterranean Sea do not mix with each other, because they are separated by a sea. This isolation could have given rise to a separate subspecies in North Africa (C. b. algirica). Froufe et al. (2013) state that over a long term an allopatric speciation process could even be taking place. The results presented here show that the Iberian populations are clearly different from that located in North Africa (Morocco) (Fig. 5) and therefore support the hypothesis that they are separate population groups, without reproductive contact that allows gene flow. Furthermore, the population at Monachil (Sierra Nevada), the most southern and possibly also the most isolated of those studied on the Iberian Peninsula, is the most different from the other peninsular populations. In any case, in order to determine if this is true, it is necessary to study in more detail the genetical and anatomical characteristics of the populations of $C$. boltonii in North Africa and Sierra Nevada.

The Central System of populations on the Iberian Peninsula are clearly a distinct group. The eastern populations resemble those in the North. This indicates that they may have had a common origin, probably located in the North of the Iberian Peninsula. From there they would have spread south along two routes, one following the mountains in the North (populations 2, 3, 4, and 5) (Fig. 1) and the other the mountains in the centre, with both routes meeting in the mountains in northern Portugal (population 1).

In summary, genetic studies (Froufe et al., 2013) along with biometric analyses can be used for grouping or segregating different $C$. boltonii populations. This method could also be used for studying populations in other areas where this species is present, and even those of other species of Cordulegaster morphologically similar to C. boltonii (Corso, 2019).

ACKNOWLEDGEMENTS. Exuviae from the Sierra Nevada were collected by Á. Romero (Granada). C. Díaz (Cuenca), B. Tens and V. Rincón (Ávila), C. Lobón, G. Sanz, T. Velasco and P. Carpintero (Valladolid), L. Nunes (Castelo Branco) and J. Márquez (Sevilla) helped with the field work. This work was funded by the European University Miguel de Cervantes support for Research Projects.

\section{REFERENCES}

Ardila-Garcia A.M. \& Gregory T.R. 2009: An exploration of genome size diversity in dragonflies and damselflies (Insecta: Odonata). - J. Zool. 278: 163-173.

ARNQVist G. \& Johansson F. 1998: Ontogenetic reaction norms of predator-induced defensive morphology in dragonfly larvae. Ecology 79: 1847-1858.

Boudot J.-P. \& JACQuemin G. 1995: Revision of Cordulegaster boltonii (Donovan, 1807) in southwestern Europe and northern Africa with description of $C$. b. iberica ssp. nov. from Spain (Anisoptera: Cordulegastridae). - Odonatologica 24: 149173.

Cabuga C.C., Estaño L.A., Abelada J.J.Z., De la Cruz I.N.B., AngCo M.K.A., Joseph C.C.D., Gamallo J.P.M., Lador J.E.O., Havana H.C. \& Martinez P.J.A. 2017: Landmark based geometric morphometric analysis describing sexual dimorphism in wings of Neurothemis terminata (Ris, 1911) from Mt. HilongHilong, Philippines. - Comput. Ecol. Softw. 7: 65-81.
Casanueva P., Carpintero P., Hernández M.A., Santamaría T. \& CAmpos F. 2017a: A biometric analysis of exuviae of Anax imperator Leach, 1815 (Odonata, Aeshnidae) in lagoons of Salamanca province, Spain. - Boln. Asoc. Esp. Entomol. 41: 197-210.

Casanueva P., Hernández M.A., Campos F. \& Santamaría T. 2017b: Boyeria irene (Fonscolombe, 1838) and Cordulegaster boltonii (Donovan, 1807) (Odonata): two strategies of substrates for emergence in the same habitat. - Graellsia $\mathbf{7 3}$ : e059, 6 pp.

Casanueva P., Hernández M.A. \& Campos F. 2017c: Does the size of the exuviae of Cordulegaster boltonii (Donovan, 1807) (Odonata: Cordulegastridae) fluctuate during the emergence period in mountain rivers? - Boln. Soc. Entomol. Aragon. 61: 271-272.

CoRbet P.S. 2004: Dragonflies: Behaviour and Ecology of Odonata. Revised Edition. Harley Books, Colchester, 829 pp.

Conso A. 2019: Morphological variability of Cordulegaster trinacriae in Italy (Odonata: Cordulegastridae). - Odonatologica 48: 175-201.

Ferreras-Romero M. \& Corbet P.S. 1999: The life cycle of $C o r$ dulegaster boltonii (Donovan, 1807) (Odonata. Cordulegastridae) in the Sierra Morena Mountains (southern Spain). - Hydrobiologia 405: 39-48.

Froufe E., Ferreira S., Boudot J.P., Alves P.C. \& Harris D.J. 2013: Molecular phylogeny of the Western Palaearctic Cordulegaster taxa (Odonata: Anisoptera: Cordulegastridae). Biol. J. Linn. Soc. 111: 49-57.

Hančínová B. 2014: Local Dispersal of Golden-Ringed Dragonfly Cordulegaster boltonii. MSc. Thesis, Charles University, Prague, $47 \mathrm{pp}$.

JACQUEMIN G. \& Boudot J.P. 1999: Les Libellules (Odonates) $d u$ Maroc. Societé Française d'Odonatologie, Bois d'Arcy, 150 pp.

JOHANSSON F. 2002: Reaction norms and production costs of predator-induced morphological defences in a larval dragonfly (Leucorrhinia dubia: Odonata). - Can. J. Zool. 80: 944-950.

JOHANSSON F. \& WAHLSTRÖM E. 2002: Induced morphological defence: evidence from whole-lake manipulation experiments. Can. J. Zool. 80: 199-206.

Kohli M.K., Schneider T., Müller O. \& Ware J.L. 2014: Counting the spots: a molecular and morphological phylogeny of the spotted darner Boyeria (Odonata: Anisoptera: Aeshnidae) with an emphasis on European taxa. - Syst. Entomol. 39: 190-195.

LANDWER B.H.P. \& Sites R.W. 2006: Variability in larval character states used to distinguish between species of Pantala Hagen (Odonata: Libellulidae). — Fla Entomol. 89: 354-360.

LEE Y-H. \& LIN C-P. 2012: Morphometric and genetic differentiation of two sibling gossamer-wing damselflies, Euphaea formosa and E. yayeyamana, and adaptive trait divergence in subtropical East Asian islands. - J. Insect Sci. 12: 53, 17 pp.

McCauley S.J., Davis C.J. \& Werner E. 2008: Predator induction of spine length in larval Leucorrhinia intacta (Odonata). Evol. Ecol. Res. 10: 435-447.

McPeer M.A. 1990: Determination of species composition in the Enallagma damselfly assemblages of permanent lakes. Ecology 71: 83-98.

Morin P.J. 1984: The impact of fish exclusion on the abundance and species composition of larval odonates: results of shortterm experiments in a North Carolina farm pond. - Ecology 65: 53-60.

Stoks R., Nystrom J.L., May M.L. \& McPeek M.A. 2005: Parallel evolution in ecological and reproductive traits to produce 
cryptic damselfly species across the Holarctic. - Evolution 59: 1976-1988.

VerschuRen D. 1989: Revision of the larvae of West-Palaearctic Cordulegaster Leach 1815 (Odonata, Cordulegastridae) with a key to the considered taxa and a discussion on their affinity. Bull. Annls Soc. R. Belge Entomol. 125: 5-35.

Received January 29, 2020; revised and accepted April 7, 2020 Published online May 29, 2020 